\title{
Knowledge Management and Innovation Capacity
}

\author{
Shadi Ebrahimi Mehrabani (Corresponding author) \\ Department of Computer Technology, Islamic Azad University, Dehaghan Branch \\ Dehaghan, Iran \\ E-mail: ebrahimish@yahoo.com
}

Maziar Shajari

Department of Computer Technology, Islamic Azad University, Dehaghan Branch

Dehaghan, Iran

E-mail: mshajari@gmail.com

Received: February 13, 2012 Accepted: February 27, 2012 Published: April 1, 2012

doi:10.5296/jmr.v4i2.1390～URL: http://dx.doi.org/10.5296/jmr.v4i2.1390

\begin{abstract}
We are living in an era where our capacity to intelligently use knowledge basically determines the future. Knowledge management is designed to present strategy, process, and technology to increase organizational learning and performance. In addition, it can help to develop the organizational innovation capacity. While there are a lack of research on the relation between knowledge management and innovation capacity in Iranian organizations, this study aims to identify any effect of knowledge management processes on innovation capacity. This study applies the structural equation modeling (SEM) to examine the research framework which was based on a survey of 240 knowledge workers from 30 manufacture factories in Iran. The results show that four of seven processes of knowledge management include knowledge creation, knowledge organization, knowledge dissemination, and knowledge application were strongly associated with factories innovation capability. Other three knowledge management factors include knowledge identification, knowledge storage, and knowledge collection that were recognized as factors not associated with those factories innovation capability. A post-hoc analyses was performed to achieve further information to conclude the study. The results of this research paper can be used by managers to implement their knowledge management process more effectively in order to increase their innovation capacity.
\end{abstract}

Keywords: Knowledge management process, Knowledge creation, Knowledge organization, 
Knowledge dissemination, Knowledge application, Innovation capacity 


\section{Introduction}

Knowledge is an organized group of data and information that people in business and other organizations create and maintain through rules and procedures (Bhatt, 2001). Knowledge management is the set of structures, methods, and technologies organized to deliver strategically useful knowledge throughout an organization (Guns \& Valikangas, 1998). Knowledge management is a complex, and dynamic subject which applies the systematic vision that considers all details and processes of managing the knowledge. Nowadays many organizations and firms believe that knowledge is the most important wealth of their organizations but usually in action they do not rely on it. One of the most important reasons is that organizations usually do not know that how they use the knowledge. However, there are many approaches and models in knowledge management; the effectiveness of each model depends on the organizational situations (Abtahi \& Salavati, 2007). One of the important issues for manufacturing factories is to sustain competitiveness by using their innovation capacities. As explained by many researchers, knowledge management influences on innovation but searching in literature shows a lack of empirical research on this field. Especially in Iranian factories there is not any research to indicate the relationship between knowledge management and innovation capacity. To fill this gap, this study tries to shed light the relationship between knowledge management processes and innovation capacity in manufacturing factories.

\section{Knowledge Management}

During the years, evolution of societies passed through three phases. The years before 1800, was the agricultural era in which the main concern of societies was gaining of land and production of food. In the late 1800s, societies entered the industrial era. This era which lasted until the early of 1960s brought mechanization and mass production factories for societies. In that era, the competitive advantages were depended on factors like land, labour and capital. In the late 1960s, societies started to experience of a new era called knowledge era or information age. This era which continues till today provides information technology. Competitive advantages in this era, is depended on the learning faster than competitors and finding exclusive knowledge (Grant, 2001). In these days, however, land, labour and capital are important resources to manage. Their significance is replaced with knowledge which is considered as a source to organizational success.

There are many definitions of knowledge management in the literature (Darroch, 2003). One of the general and brief definitions was stated by Senge et al. (1999). They explained that the word "know" means "to know" and the suffix "ledge" initially means "process" or "action". Therefore, Knowing this knowledge can be described as "the capacity for effective action" (Senge, Kleiner, Roberts, Ross, \& Smith, 1999).

Knowledge management is illustrated as a multi dimensional construct with a great quantity of inter related characteristic (Darroch, 2003). For example, O’Dell and Grayson (1998) in their model of knowledge management stated that the process of knowledge management is done by seven factors. They are knowledge creation, knowledge identification, knowledge collection, knowledge organizing, knowledge dissemination, knowledge evaluation and 
adoption, and knowledge application (O'dell \& Grayson, 1998). One of the practical definitions provided by Probst (1999) explains that knowledge management contains of six major factors are: knowledge identification, knowledge acquisition, knowledge development, knowledge dissemination, knowledge preservation and knowledge application. Lawson (2002) described the process of knowledge management by knowledge creation, knowledge capture, knowledge organizing, knowledge storage, knowledge dissemination, and knowledge application (Lawson, 2002).

In fact, the definition of knowledge management changes from organization to organization, even from program to program (Call, 2005). For the purpose of this paper, knowledge management process is defined as: the procedures that identify, create, and collect the necessary knowledge, will organize the knowledge and finally manage the storage, dissemination and application of knowledge in the organizations. Following are general definitions of the constructs.

Knowledge identification: Knowing the available knowledge and skill both inside and outside the organizations is important for companies and organizations (Probst, 1999). Knowledge identification is one of the main aspects of knowledge management. Managers can understand the weaknesses of their employees and try to adjust the employee's knowledge and abilities with required knowledge in the organizations by identifying employee's knowledge (Afraze, 2005).

Knowledge creation: knowledge can be created through different ways (O'dell \& Grayson, 1998). Creation and acquiring knowledge can be done through different sources such as employees, customers, business partners and competitors (Lawson, 2002).

Knowledge collection: An individual can collect intellectual capital by talking to other employees. Knowledge collection is the most important practice and you can share it by knowledge donating. Knowledge sharing is also, part of knowledge management. In an organization, effective development of knowledge sharing practices will change the behaviors and attitudes of the employees toward the readiness to donate and collect knowledge (Van den Hooff \& Van Weenen, 2004).

Knowledge organization: knowledge organizing includes activities of knowledge processing to transform knowledge to a good form (O'dell \& Grayson, 1998). Having a policy to review knowledge on regular basis, keeping knowledge up to date, having mechanisms for filtering, cross listening, integrating different sources and types of knowledge, giving feedback to employees on their ideas and knowledge are some construct to organizing the knowledge (Lawson, 2002).

Knowledge storage: If organizations do not want to loos their valuable knowledge, they must select a form of knowledge process for suitable storage and preservation (Probst, 1999). Organizations have to use databases and information technology applications to store knowledge for easy access by all employees (Lawson, 2002).

Knowledge dissemination: Knowledge dissemination is a way of transmitting knowledge to other employees who need that knowledge in the organization (Adli, 2005). Before 


\section{Macrothink

knowledge can be exploited at the organization levels, it has to be distributed and shared through the organization (Bhatt, 2001).

Knowledge application: Organizational knowledge needs to be used in a company's products, processes, and services. To keep the competitive advantage, organizations have to place the right kind of knowledge in the right form (Bhatt, 2001). In fact, knowledge application is the final aim of knowledge management (Probst, 1999).

\section{Innovation and Knowledge Management}

In the literature, innovation is usually illustrated by two approaches. They are traditional structuralism approach and process oriented approach. In traditional structured approach, innovation is defined as an entity with fixed parameters that some external suppliers create to give to the user (Wolfe, 1994).

Process oriented approach dispute that innovation is not an entity to be moved from one place to another, rather it has to be seen as a complex process that follows a politically charged design and also, a decision process which regularly is related to several social groups within the organizations. Therefore, innovation is a process of growth and implementation of new ideas by people who eventually communicate with other people in organizations (Van de Ven, 1986).

Knowledge management has two important benefits at the organizational level. First, through increasing efficiency, productivity, quality and innovation the organizational performance will be improved; then better decision making, improving process, data integration and broad collaboration will emerge (Cong \& Pandya, 2003). Knowledge management has to be considered as an ongoing process which does not have to be limited to separate steps that use particular applications. Instead, it must be considered as a continuous process to serve the organization's needs (Lakshman, 2007).

On the other hand, innovation processes are going to be more interactive and more reliant on distributed knowledge. Need for innovation within and across the organization has been increased (Swan, Newell, Scarbrough, \& Hislop, 1999). Several researches have recognized the effect of an effectiveness knowledge management in innovation (Nonaka \& Takeuchi, 1995; Antonelli, 1999; Carneiro, 2000; Darroch, 2005).

Consequently, searching in the Persian literature shows a lack of research on knowledge management and innovation. Therefore, the main purpose of this study is to find the effect of knowledge management on factories innovation capacities. Figure 1 demonstrates the research framework, followed by set of hypotheses. 


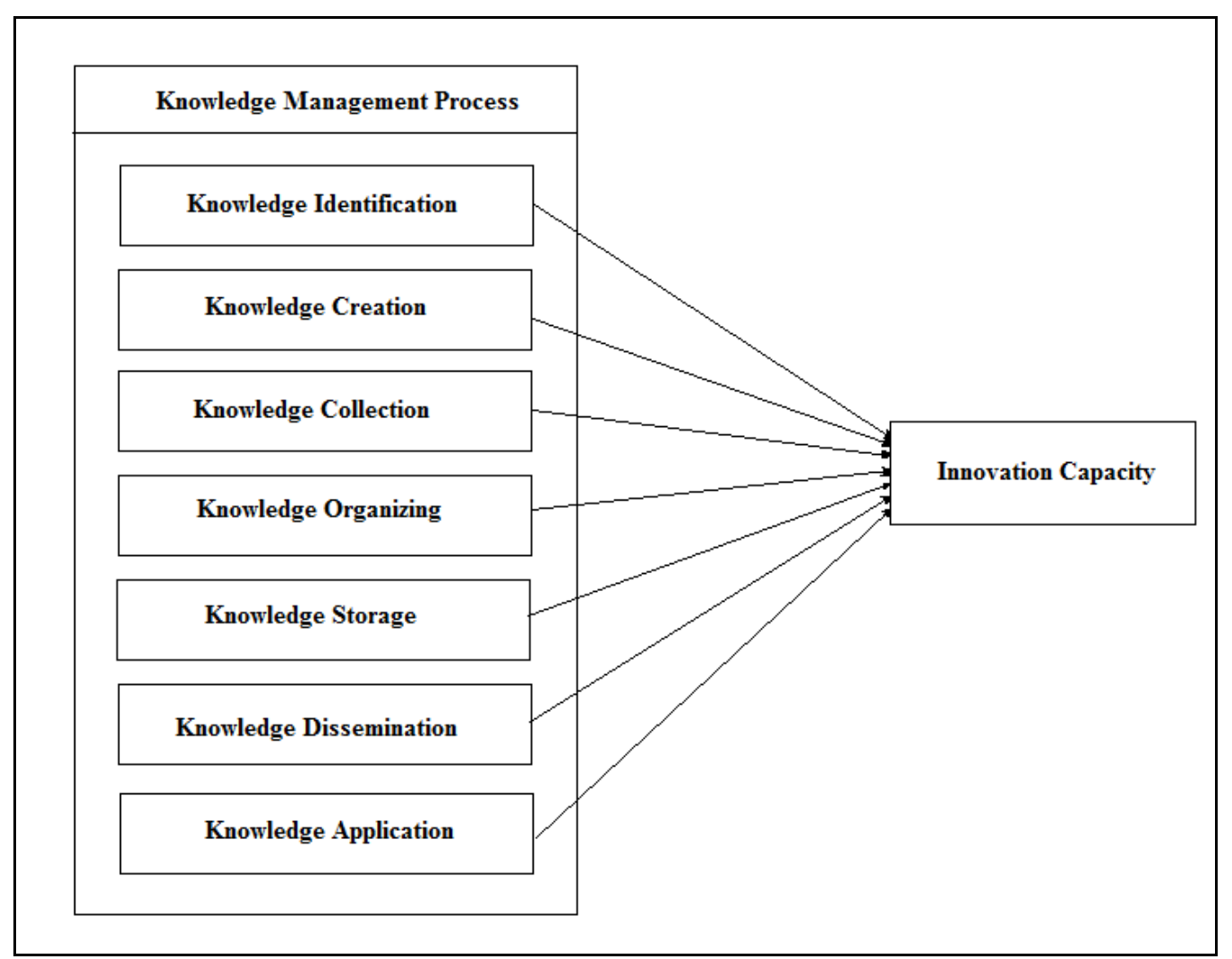

Figure 1. Conceptual Framework

H1: Knowledge identification has effect on factories innovation capacity.

H2: Knowledge creation has effect on factories innovation capacity.

H3: Knowledge collection has effect on factories innovation capacity.

H4: Knowledge organizing has effect on factories innovation capacity.

H5: Knowledge storage has effect on factories innovation capacity.

H6: Knowledge dissemination has effect on factories innovation capacity.

H7: Knowledge application has effect on factories innovation capacity.

\section{Methodology}

The main purpose of this research paper is to identify the key processes of knowledge management that affect innovation in manufacturing factories in Iran. Providing a framework for this relationship can help the factories to implement their knowledge management more effectively and also, may use by other factories. While this research used the survey (questionnaire) and Structure Equated Modeling (SEM) to understand the relationship between knowledge management process and innovation capacity, a post-hoc-analyses (interview) help to clarify the conclusion of the survey. 


\subsection{Sampling}

This research was done in several manufacturing factories in Iran, province of Tehran (the capital of Iran) and Esfahan (third largest city in Iran with many industries). Islamic Republic of Iran is located in Middle East, Asia. Iran is the 18th large country in the world with over 75 million populations. However, based on a cluster sampling, since there are so many manufacturing factories in Iran only 30 of them were chosen as places of study.

In these factories, the numbers of knowledge workers were estimated about 2000. Therefore, the sample size was calculated 322 people. After collecting the questionnaires and outlier detection process, the usable questionnaires for analyzing were 240 which represent a response rate of 74.5 percent.

\subsection{Measure}

The questionnaire's items that used to operation the constructs were mainly adapted from previous studies and modified for use in the knowledge management context. Knowledge management items were derived from knowledge management assessment instrument by Liebowitz (2004) and, knowledge sharing practice Questionnaire by De Vries et al. (2006). Six items measured the innovation capabilities which were derived from the items introduced by Lin (2007), which focused on firm innovation capacity. Summary of construct, which is used by questionnaire, is presented in Table 1. 
Table 1. Summary of Construct Using by Questionnaire

\begin{tabular}{|c|c|}
\hline Constructs & Related Items \\
\hline $\begin{array}{l}\text { Knowledge } \\
\text { Identification }\end{array}$ & $\begin{array}{l}\text { Knowing the available knowledge and skill both inside and outside the } \\
\text { organizations. } \\
\text { Trying to adjust the employee's knowledge and abilities with require knowledge } \\
\text { Identifying the employee's knowledge. } \\
\text { Identifying the useful knowledge which is available in the organizational working } \\
\text { process. }\end{array}$ \\
\hline Knowledge Creation & $\begin{array}{l}\text { Having the mechanisms of creating and acquiring knowledge from different } \\
\text { sources such as employees, customers, business partners and companies. } \\
\text { Encouraging the employees to exchange their knowledge and ideas. } \\
\text { Giving rewards for new ideas and knowledge. } \\
\text { Having mechanism for creating new knowledge from existing knowledge. }\end{array}$ \\
\hline Knowledge Collection & $\begin{array}{l}\text { Collecting the useful knowledge which identified from various sources. } \\
\text { Giving the possibility to ask when there is a need to certain knowledge } \\
\text { Giving the information about what we know. } \\
\text { Allowing others to ask about the abilities when there is a need to learn something. }\end{array}$ \\
\hline $\begin{array}{l}\text { Knowledge } \\
\text { Organizing }\end{array}$ & $\begin{array}{l}\text { Having a policy to review knowledge on a regular basis and keep them up to date. } \\
\text { Having the mechanisms for filtering, cross listing and integrating different types of } \\
\text { knowledge. } \\
\text { Giving feedback to employees about their ideas and knowledge. } \\
\text { Having processes for applying knowledge learned from experiences and match } \\
\text { sources of knowledge to problems and challenges. }\end{array}$ \\
\hline Knowledge Storage & $\begin{array}{l}\text { Using the databases, repositories and information technology applications to store } \\
\text { the knowledge for easy access by all employees. } \\
\text { Using various written devices such as newsletter, manuals to store the knowledge } \\
\text { which capture from the employees. } \\
\text { Having different publications to display the capture knowledge. } \\
\text { Having mechanisms to patent and copyright ne knowledge. }\end{array}$ \\
\hline $\begin{array}{c}\text { Knowledge } \\
\text { Dissemination }\end{array}$ & $\begin{array}{l}\text { Having a form of knowledge that is readily accessible to employees who need it. } \\
\text { Sending out timely reports with appropriate information to employees. } \\
\text { Having libraries, resource centre and other forums to display and distribute the } \\
\text { knowledge. } \\
\text { Having lecturers, conferences and training sessions to sharing knowledge }\end{array}$ \\
\hline $\begin{array}{l}\text { Knowledge } \\
\text { Application }\end{array}$ & $\begin{array}{l}\text { Having different methods for employees to further develop their knowledge. } \\
\text { Having mechanisms to protect the knowledge inside and outside the organizations. } \\
\text { Appling knowledge to critical competitive needs and quickly links sources of } \\
\text { knowledge in problem solving. } \\
\text { Having methods to analysing and evaluating knowledge to generate new patterns } \\
\text { and knowledge for future use. }\end{array}$ \\
\hline Innovation Capacity & $\begin{array}{l}\text { Trying out the new Ideas. } \\
\text { Seeking new ways to doing things. } \\
\text { Being creative in operating methods. } \\
\text { Marketing the new products and services frequently. } \\
\text { Increasing the numbers of new products in last five years. }\end{array}$ \\
\hline
\end{tabular}

\section{Data Analysis and Results}

Ahead of analyzing the data a pilot study was done by distributing thirty questionnaires randomly in some related factories. After gathering the data, reliability of questionnaire was calculated by Cronbach's alpha value. This value showed the over level of 0.70 for each item which illustrated the reliability of the questioner. After that, to validate the research framework, data analysis was done using structural equation modeling (SEM). For this purpose, at first for validation of instrument the measurement model was examined and it followed by an analysis of the structural model for testing associations hypotheses.

\subsection{Measurement Model}

The measurement model with all eight constructs was evaluated by using confirmatory factor analysis. The model fit indicators that were used for model fit in this study are normal chi-square (CMIN/df), goodness-of-fit index (GFI), adjusted goodness-of-fit (AGFI), 
comparative fit index (CFI), Tucker Lewis Index (TLI), and the root mean square error of approximation (RAMSEA). By testing each variable separately, some minor modifications were done in the items to get good values of mentioned indicators. These modifications are including connecting some errors as it is illustrated in Figure 2. The results of the values of final model fit indicators are illustrated in Table 2.

Table 1. Summary of Model Fit Indicators after Minor Modifications

\begin{tabular}{|c|c|c|c|c|c|c|c|}
\hline ITEM & CMIN/df & $\begin{array}{c}\text { P- } \\
\text { Value }\end{array}$ & GFI & AGFI & CFI & TLI & RMSEA \\
\hline KI & 0.72 & 0.39 & 1 & 0.985 & 0.998 & 1 & 0 \\
\hline KR & 1.04 & 0.30 & 0.998 & 0.975 & 1 & 0.999 & 0.014 \\
\hline KC & 0.55 & 0.45 & 0.999 & 0.988 & 1 & 1 & 0 \\
\hline KO & 1.95 & 0.14 & 0.992 & 0.959 & 0.995 & 0.985 & 0.063 \\
\hline KS & 0.43 & 0.64 & 0.998 & 0.991 & 1 & 1 & 0 \\
\hline KD & 1.20 & 0.30 & 0.995 & 0.974 & 0.998 & 0.995 & 0.029 \\
\hline KA & 2.21 & 0.11 & 0.987 & 0.956 & 0.962 & 0.991 & 0.071 \\
\hline INN & 1.53 & 0.17 & 0.987 & 0.962 & 0.992 & 0.984 & 0.047 \\
\hline
\end{tabular}

The measurement model was changed regarding the modifications and it was used for last model fit. First evaluation showed that some indicators (GFI, AGFI, CFI, and TLI) do not have acceptable values, therefore, the final measurement model is not fit and it needs to be modified (table 3). As table 4 shows question KS4 correlates with other questions or items and was repeated more. Then, in the next step, this question must be deleted.

Table 2. Model Fit Indicators for Measurement Model

\begin{tabular}{|c|c|c|c|c|c|c|}
\hline & CMIN/df & GFI & AGFI & CFI & TLI & RMSEA \\
\hline $\begin{array}{c}\text { Total } \\
\text { Model }\end{array}$ & 2.91 & 0.80 & 0.76 & 0.755 & 0.721 & 0.09 \\
\hline
\end{tabular}

Table 3. Item’s Regression Weight

\begin{tabular}{|lll|rr|}
\hline & & & \multicolumn{1}{|c|}{ M.I. } & Par Change \\
\hline INN1 & $<---$ & KS4 & 163.150 & .768 \\
KS4 & $<---$ & INN & 74.761 & .976 \\
KS4 & $<---$ & INN2 & 46.121 & .314 \\
KS4 & $<---$ & INN1 & 218.439 & .873 \\
\hline
\end{tabular}




\section{Macrothink}

After dropping question KS4, the value of indicators will be as table 5 . A value more than 0.8 for GFI and AGFI would be good for model fit (Chin \& Todd, 1995). Therefore, the combination of these results suggested that measurement model demonstrates a good level of model fit (Figure 2).

Table 4. Model Fit Indicators for Measurement Model after dropping KS4

\begin{tabular}{|c|c|c|c|c|c|c|}
\hline & CMIN/df & GFI & AGFI & CFI & TLI & RMSEA \\
\hline $\begin{array}{c}\text { Total } \\
\text { Model }\end{array}$ & 1.58 & 0.851 & 0.818 & 0.915 & 0.902 & 0.05 \\
\hline
\end{tabular}

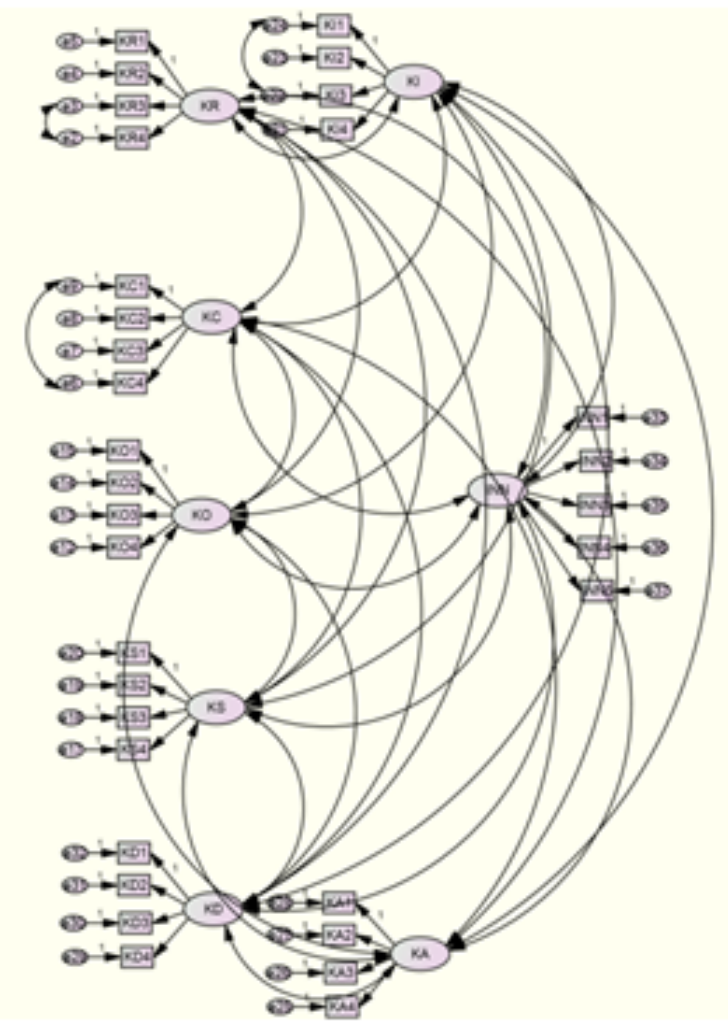

Figure 2. Final Measurement Model

\subsection{Structural Model}

The second step in model estimation was to examine the significance of each hypothesis. Multiple regression analysis was applied to test the hypothesis. The results of regression analysis are depicted in table 6 . This table shows that the model needs modifications. Relations which showing values more than 0.05 are not significant and must be deleted from the model. 


\section{Macrothink}

Table 5. Regression Weights of Initial Structural Model

\begin{tabular}{|c|c|c|c|c|c|c|}
\hline & & & Estimate & S.E. & C.R. & $\mathrm{P}$ \\
\hline INN & $<---$ & KI & .047 & .037 & 1.263 & .207 \\
\hline INN & $<---$ & $\mathrm{KR}$ & -.160 & .040 & -3.965 & $<0.001$ \\
\hline INN & $<---$ & KC & -.102 & .071 & -1.446 & .148 \\
\hline INN & $<---$ & $\mathrm{KO}$ & .116 & .037 & 3.175 & .001 \\
\hline INN & $<---$ & KS & .035 & .031 & 1.140 & .254 \\
\hline INN & $<---$ & KA & 1.152 & .189 & 6.093 & $<0.001$ \\
\hline INN & $<---$ & KD & .245 & .055 & 4.438 & $<0.001$ \\
\hline
\end{tabular}

By dropping relations with more than 0.05 p-values, three relations were omitted. They were: KS- INN, KI-INN, and KC- INN. Following we continue with modification steps, all remaining relations have significant regression weight. They are shown in table 7.

Table 6. Regression Weights of Final Structural Model

\begin{tabular}{|ll|rccc|}
\hline & & \multicolumn{1}{|c}{ Estimate } & S.E. & C.R. & P \\
\hline INN $<---$ & KR & -.158 & .040 & -3.925 & $<0.001$ \\
INN $<---$ & KO & .132 & .037 & 3.528 & $<0.001$ \\
INN $<---$ & KA & 1.148 & .190 & 6.040 & $<0.001$ \\
INN $<---$ & KD & .285 & .059 & 4.877 & $<0.001$ \\
\hline
\end{tabular}

The results demonstrate that knowledge creation, knowledge organization, knowledge dissemination, and knowledge application positively influence the factories innovation capacity. It means that hypotheses H2, H4, H6, and H7 were supported. However hypotheses $\mathrm{H} 1, \mathrm{H} 3$, and H5 were not supported and then knowledge identification, knowledge storage, and knowledge collection did not show any relation with factories innovation capacity. Figure 3, shows the final accepted model of this study named KMI (Knowledge Management and Innovation) model. 


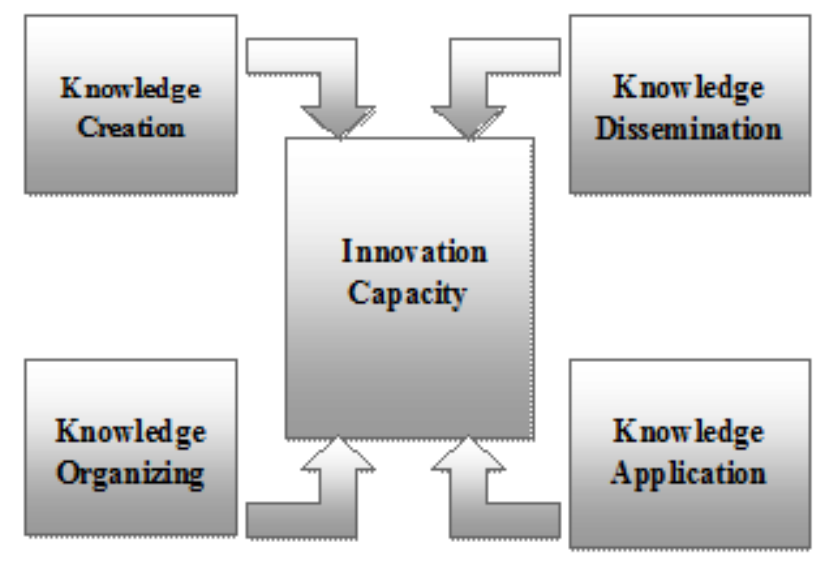

Figure 1. KMI Model

\section{Post-Hoc-Analysis}

As three hypotheses of the study were not supported, a post-hoc-analysis was done in order to understand the survey's results. The post-hoc analysis was executed by three interviews with top managers in different factories. To have suitable results, interviewees were selected purposefully. The main objective of these interviews was to find out reasons for unsupported hypotheses.

As a result, interviewees believed that knowledge identification, storage and collection might be factors, which do not have direct impact on innovation. Furthermore, they stated that in their environment, factors such as sharing, developing and creating the knowledge can encourage employees to think innovatively. Moreover, they asserted that using methods like rewarding and feed backs are very helpful for the innovation thinking.

They stated that knowledge identification, storage and collection do not have direct impact on innovation capacity, knowledge identification can help the knowledge creation; knowledge storage can impact the knowledge organization; and knowledge collection can help to the impact of knowledge dissemination on innovation capacities. Therefore, indirect effects of these factors can be examined in a future survey.

\section{Conclusion}

In an era where innovations capacity as a competitive advantage is perceived to be linked to the knowledge management, considerable interest in understanding the knowledge management process continues to be the trend. Moreover, knowledge management process can influence innovation capacity in the organizations. An important component of this understanding in many organizations would be the re-configuration of the role of knowledge management in increasing innovation capacities, which needs to be analyzed by managers.

In this study, the results from a structural equation modeling approach support four hypothesized relations. The findings show that knowledge creation, knowledge organization, 
knowledge dissemination, and knowledge application were strongly associated with factories innovation capability. Knowledge identification, knowledge storage, and knowledge collection were realized as factors which were not associated with factories innovation capability. Therefore, hypothesis number 2, 4, 6 and 7 were supported and hypothesis number 1,3 , and 5 were not supported in the places of the study.

Post-hoc analysis shows that cultural context may influence the relationships. For example to display the innovation and creativity, Iranian workers are more encouraged by a collectivism culture.

\section{Discussion and Suggestion to Future Research}

This study has advantages from both theoretical and practical perspectives. Theoretically, this study proposed a research framework for empirical studies to link knowledge management processes and factories innovation capability. From a practical perspective, the relationship between knowledge management processes and factories innovation capability may provide a clue regarding how factories can manage their knowledge to keep up their innovation capacity. From a managerial perspective, this study identified several factors which are necessary to successful knowledge management, and discussed the application of these factors for developing innovation capacity. While the results of this study confirm that knowledge creation, knowledge organization, knowledge dissemination, and knowledge application are the factors which influence the innovation capacity, managers need to give more attention to establish these factors to get more innovation capacity.

Further research may use the presented factors as determinants for knowledge management process. In addition, the research model can be tested by further using samples from other countries or organizations. Future studies can also, gather longitudinal data to examine the relationship between variables. Furthermore, the moderator role of personal character (such as age, level of education, and working experiences) and organizational characteristics (such as firm size and industry type), can be examined on this relationship. Moreover, as illustrated in post-hoc analysis, the indirect effect of knowledge identification, knowledge storage and knowledge collection can be investigated in the model in future.

\section{References}

Abtahi, H., \& Salavati, A. (2007). Knowledge management in the organization. Tehran, Iran: peivand no.

Adli, F. (2005). Knowledge Management: Tranaction to Past Knowledge. Tehran: Andishe.

Afraze, A. (2005). Knowledge Management (Concepts, Models, Measuring and implementing). Tehran: Moalef.

Bhatt, G. D. (2001). Knowledge Management in Organozations: Examining the Interaction Between Technologeis, Techniques, and People. Journal of Knowledge Management, 5 (1), 68-75. http://dx.doi.org/10.1108/13673270110384419

Call, D. (2005). Knowledge management- not rocket science. Journal of Knowledge 
management, 9 (2), 19-30. http://dx.doi.org/10.1108/13673270510590191

Chin, W. W., \& Todd, P. (1995). On the Use, Usefulness, and Ease of Use of Structural Equation Modeling in MIS Research: A Note of Caution. MIS Quarterly, 19 (2), 237-246. http://dx.doi.org/10.2307/249690

Cong, X., \& Pandya, K. (2003). Issues of Knowledge Management in the Public Sector. Electronic Journal of Knowledge Management, 1 (2), 25-33.

Darroch, J. (2003). Developing a measure of knowledge management behaviors and practices. 7 (5), 41-54.

De Vries, R. E., Van den Hoff, B., \& De Ridder, J. A. (2006). Explaining Knowledge Sharing: The Role of Team Communication Styles, Job Satisfaction, and Performance Beliefs. Communication Research, 33 (2), 115-135. http://dx.doi.org/10.1177/0093650205285366

Grant, R. M. (2001). Managing industrial knowledge: Creation, transfer and utilization. London: Sage Publications.

Guns, W., \& Valikangas, L. (1998). Rethinking knowledge work: Creating value through. Menlo Park, CA: SRI Consulting.

Lakshman, C. (2007). Organizational knowledge Organizational knowledge approach. Leadership \& Organization Development Journal, 28 (1), 51-75. http://dx.doi.org/10.1108/01437730710718245

Lawson, S. (2002). knowledge management assessment instrument. Nova Southeastern University.

Liebowitz, J. (2004). Addressing the human capital crisis in the federal government: A knowledge management perspective. New York: Butterworth-Heinemann.

Lin, H.F. (2007). Knowledge sharing and firm innovation capability: an empirical study. International Journal of Manpower, $28 \quad$ (3/4), 315-332. http://dx.doi.org/10.1108/01437720710755272

O'dell, C., \& Grayson, C. (1998). only we knew what we know: identification and transfer of internal best practices. California Management Review, 4 (3), 154-174.

Probst, G. (1999). Practical Knowledge Management: A Model That Works. In G. Probst, S. Roub, \& K. romhardt, Managing Knowledge: Building Block for Success (pp. 17-29). WILEY.

Senge, P., Kleiner, A., Roberts, C., Ross, R., \& Smith, B. (1999). The dance of change: The challenges of sustaining momentum in learning organizations. New York, NY: Doubleday.

Van den Hooff, B., \& Van Weenen, F. d. (2004). Committed to Share: Commitment and CMC Use as Antecedents of Knowledge Sharing. Knowledge and Process Management, 11 (1), 13-12. http://dx.doi.org/10.1002/kpm.187 